Theories \& Applications, the International Edition

Printed Version : (ISSN 2090-5262)

Online Version : (ISSN 2090-5270)

July 2014, Volume 4, No. 2 Pages (99 - 102)

\title{
Effects of Ballistic Resistance Training on Swimming Start.
}

\section{Nashua Wahdan}

Faculty of physical education - Helwan university, Egypt.

Azza Abdelmnsef

Faculty of physical education - Helwan university, Egypt.

\begin{abstract}
Ballistic training, also known as power training, is a form of strength training that entails an athlete lifting, accelerating and finally releasing a weight rather than slowly lowering it. It was first used among elite athletes who were trying to develop explosiveness to help them improve their speed. The purpose of this study was to determine whether ballistic resistance training would improvement the performance of swim starts for female students. Ten, grade 4 female students from a physical education program participated in the study. The students' mean height was $1.77 \pm 3.02$ meters, with a mean age of $21.14 \pm 1.25$ years. The subjects were divided equally into two groups. The experimental group completed 6 weeks of ballistic resistance training while the control group participated in a traditional training program. Statistical analysis of the results was carried out using SPSS software. The results showed that the experimental group had significantly higher power and faster swimming starts than the control group. Under the conditions of our study, an intervention using ballistic resistance training for 6 weeks had beneficial effects on performance levels of swimming starts and power.
\end{abstract}

Keywords: power training, Strength, swimming start.

\section{Introduction}

Several performance-determining factors are apparent during swim training. One of these factors is strength. Because the positive correlation between a swimmer's power (defined as strength $\mathrm{x}$ velocity) and their swim performances (Hirofumi et al., 1993; Johns et al., 1992; Toussaint and Vervoorn, 1990), swim instructors often try to improve power through strength training. They assume that strength training leads to a greater performance capacity and, therefore, improves swim performances. Strength training is carried out both in and out of water. However, it is uncertain whether dry-land strength training leads to improved sprint performance capacity during swimming.

There are many methods and theories regarding the design of an effective training program that can improve performance. Use of ballistic training to develop an explosive force is one method. This method can be used to overcome the lack of speed resulting from weight-training by allowing the player to explode speed through the stages of movement. As there is an increase in speed over the full range of movement, speed does not begin to decline until after the weight is released. This type of training is usually used between traditional workouts of the upper body, such as throwing medicine balls, as well as training the lower body, such as jumps. Instructors in sports activities characterized by explosive performance devise training methods that enhance performance in these sports.

One of the most important methods for developing power is ballistic training. Traditional strength training (nonballistic) does not allow the muscle to reach the maximum ability after a full second from the start. On the contrary, ballistic training forces the player to access the ability of the muscle to reach the maximum faster within the limits 0.2 seconds or less, which is the same as the speed of the arm when throwing in competitions.

Ballistic training, also called power training, was first used among elite athletes who were looking for a method to develop explosiveness. The word ballistic comes from the Greek word ballein, which means "to throw." In this type of training, the athlete accelerates and releases the weight into "free space." Common ballistic training exercises are bench throws, jump squats, cleans, snatches, and push presses. (Scheett, 2004)

Ballistic training forces the athlete's body to recruit and trigger fast twitch muscle fibers. This is important because these muscle fibers have the greatest potential for growth and strength. Ballistic training requires the muscles to adapt to contracting very quickly and also forcefully. This training requires the central nervous system to coordinate and produce the greatest amount of force in the shortest time possible. (Brandon, 2003)

Research shows that the maximum strength development becomes limited after a certain point. Once an athlete has reached a high level of strength, any further increases will lead to improvement only at the high force/slow velocity end of the curve. This means no increases in power or force at fast speeds.

By contrast, ballistic or power training has been shown to increase power and the rate of force production and is more highly correlated with athletic performance than strength 
training. Power training methods can vary in terms of force and velocity characteristics, since the description embraces a number of different approaches. Plyometric jumping or throwing exercises tend to use higher velocity and lower force, whereas Olympic lifting exercises, such as power cleans, use higher force and lower velocity. Between these two extremes lie ballistic weight exercises, such as barbell squat-jumps and bench press throws, which employ moderate forces and velocity. (Hammett and Hey, 2003)

Additional research has shown that as much as $75 \%$ of a movement can be devoted to slowing the bar down. Elliot et al., (1989) reported that during 1-RM bench presses, the bar decelerates for the final $24 \%$ of the range of movement. At $81 \%$ of $1-\mathrm{RM}$, the bar decelerates for the final $52 \%$ of the range of movement. Research has shown that for best results it is important to load the bar with the amount of weight that allows for positive acceleration to be maintained through the full range of movement of the lift. Therefore, the purpose of this study was to determine whether ballistic resistance training would improvement the performance of swim starts for female students.

\section{Material and Methods}

\section{Participants}

Ten, grade 4 female students from a physical education program participated in the study. The mean value for the anthropometric measure of body height was $1.77 \pm 3.02$ meters; the mean age was $21.14 \pm 1.25$ years. The subjects were divided equally into two groups. The experimental group $(n=5)$ completed 6 weeks of ballistic resistance training while the control group participated in a traditional training program. All subjects were free of any medical conditions known to affect bone metabolism, such as bone fractures, osteoporosis, diabetes and cardiovascular disease. None of the participants reported use of any anti-seizure medications, alcohol or cigarettes.

\section{Training Protocol}

The 6-week in-season training program consisted of ballistic action. Newton and Kraemer, (1994) suggest that a load of $30 \%$ to $35 \% 1-\mathrm{RM}$ should be used for exercises that include free weights, such as jump squats. For many ballistic exercises the weights of the objects themselves dictate the load. The weight of medicine balls range from 2 to $6 \mathrm{~kg}$ (4.4-13 lbs) and that of kettlebells from 10 to $32 \mathrm{~kg}(22-70$ lbs).

\section{A description of exercises for ballistic power training are summarized below:}

- Balance on one foot with a switch to the other foot.

- High jump with feet together towards the chest.
- Jump in place carrying a medicine ball with the feet.

- Stand, with a medicine ball between the feet.

- Stand, with a medicine ball between the feet and jumping through a rope on ground.

- Stand, with a medicine ball on each foot, then run back and forth.

- Stand, with a medicine ball on each foot then jump up and go back and forth with feet apart.

- Stand, with a medicine ball on each foot then jump backwards, with hand and knees touching the chest.

- Stand, with a medicine ball on each foot then jump forward and stop, and throw the ball to a colleague, and the colleague does the same.

- Jump forward in a squatting position, carrying a weight of $0.5 \mathrm{~kg}$ by hand.

- Jump backwards carrying a 1-kg weight by hand.

- Go up and down carrying a 1-kg weight by hand.

- Go up and down carrying a $0.25-\mathrm{kg}$ weight attached to the foot.

- High jump forward carrying a 1-kg weight by hand.

- High jump forward carrying a $0.5-\mathrm{kg}$ weight attached to the foot.

- Jump rope carrying a $1-\mathrm{kg}$ weight by hand.

- Jump rope carrying a $0.25-\mathrm{kg}$ weight by the feet.

- Go up and down carrying a $0.25-\mathrm{kg}$ weight attached to the feet

- Stand up on the front of a chair, putting one foot on another seat, carrying a weight by two hands, then go up and down from the seat, changing foot positions.

- Jump backwards from the squatting position then jump.

- Go up and down over a box in an explosive way while carrying a $0.25-\mathrm{kg}$ weight by the feet.

\section{Statistical Analysis}

All statistical analyses were done using an SPSS statistical package. The results were reported as means \pm standard deviations (SD). The Friedman test for non-parametric data was used to determine the differences between the three measurements (pretests, midtest, and posttests) in the two groups (control and experimental). A p-value $<0.05$ was considered as statistically significant. 
Table 1

Pre-, mid- and post-tests of start distances and start times in crawl swimming.

\begin{tabular}{|c|c|c|c|c|c|c|c|}
\hline \multirow{2}{*}{\multicolumn{2}{|c|}{ Variables }} & \multicolumn{3}{|c|}{ Experimental group } & \multicolumn{3}{|c|}{ Control group } \\
\hline & & \multirow{2}{*}{\begin{tabular}{|c|}
$\begin{array}{c}\text { Pre - } \\
\text { tests }\end{array}$ \\
1.68 \\
\end{tabular}} & \multirow{2}{*}{$\begin{array}{c}\begin{array}{c}\text { Mid - } \\
\text { tests }\end{array} \\
3.48 \\
\end{array}$} & \multirow{2}{*}{$\begin{array}{c}\begin{array}{c}\text { Post - } \\
\text { tests }\end{array} \\
5.31\end{array}$} & \multirow{2}{*}{$\begin{array}{c}\begin{array}{c}\text { Pre - } \\
\text { tests }\end{array} \\
1.68\end{array}$} & \multirow{2}{*}{$\begin{array}{c}\begin{array}{c}\text { Mid - } \\
\text { tests }\end{array} \\
1.68 \\
\end{array}$} & \multirow{2}{*}{$\begin{array}{r}\begin{array}{r}\text { Post - } \\
\text { tests }\end{array} \\
1.68\end{array}$} \\
\hline \multirow{2}{*}{ Start distance } & Mean rank & & & & & & \\
\hline & $\mathbf{K}$ & \multicolumn{3}{|c|}{25.00} & \multicolumn{3}{|c|}{25.00} \\
\hline \multirow{2}{*}{ Start time } & Mean rank & 2.31 & 3.14 & 4.39 & 2.46 & 2.46 & 2.46 \\
\hline & $\mathbf{K}$ & \multicolumn{3}{|c|}{16.55} & \multicolumn{3}{|c|}{24.95} \\
\hline
\end{tabular}

Table 1 shows the significant differences between the three measurements (pre-mid and post) tests in start distance and start time for the posttests.

Table 2

Significant differences between the experimental and control groups for start distances and start times in crawl swimming.

\begin{tabular}{|c|c|c|c|c|c|c|}
\hline Variables & Groups & Rank number & Rank mean & Rank total & $\mathbf{U}$ & $P$ sign. \\
\hline \multirow{2}{*}{ Start distance } & Experimental & 3 & 1.00 & 3.00 & \multirow{2}{*}{$2.87 *$} & \multirow{2}{*}{0.009} \\
\hline & Control & 2 & 0.5 & 1.00 & & \\
\hline \multirow{2}{*}{ Start time } & Experimental & 3 & 2.5 & 7.5 & \multirow{2}{*}{$2.80 *$} & \multirow{2}{*}{0.012} \\
\hline & Control & 2 & 1.00 & 2.00 & & \\
\hline
\end{tabular}

Table 2 shows the significant differences between the two groups in start distance and start time for the experimental group.

\section{Discussion}

The results of this study demonstrated that, regardless of the exercise type, significant improvements in start distance and start time occurred. Results of the experimental group show the positive impact of a ballistic training program, which, according to Ramadan, relies on the development of muscle strength in an explosive manner (Ramadan 2003). This type of training program leads to greater improvement in the ability to perform any muscle exercises that involve jumping from a squatting position compared with what muscle training would provide for similar exercises.

These results are in agreement with several previous studies showing that ballistic exercises improve motor performance speed, as the power acquired through this type of training leads to a better motor performance for the sports activities. These studies have also shown the importance of ballistic training in increasing the ability of the muscle to contract faster and more explosively through the joint's range of movement. It was also shown that ballistic training is suitable for developing muscle speed and power as most exercises are performed explosively without decreasing velocity. Elongated muscle contraction is changed to a shortened contraction with maximum velocity (McCoy, et al. 1984; Linthorne, 2001).

Newton et al. reported that the lifting of relatively light weight loads $(30 \%$ 1-RM) at high speeds is effective for maximizing power output and that heavy loads (80\%-90\% 1-RM) have been recommended for improving maximum dynamic performance (Newton, et al. 1997). Atha described dynamic performance as strength efforts repeated several times until stopped either from fatigue or time limits (Atha, 1981).

Ballistic training overcomes one of the problems with traditional resistance training and power development, that is the deceleration of the bar in the later part of the concentric phase of movement. This can be overcome if the athlete actually throws or jumps with the weight. Ballistic resistance infers accelerative high velocity of the load or of one's self into free space (Newton and Kraemer, 1994).

In contrast, dry-land strength training has not improved swimming speed in other studies. In one study, a group of college swimmers who engaged in a combination of weight training and swim training did not improve their tethered swimming power nor their competitive swimming performances to any greater extent than a group who trained only with swimming (Zatsiorsky, 1995). The group that used resistance training performed a general weight training program, using 3 sets of 8 to 12 repetitions 3 days per week. Most of the exercises were designed to work the large muscle groups of the shoulders and trunk in ways that simulated swimming movements. Most of the exercises involved shoulder extension and adduction movements and arm extensions. Neither group demonstrated improvements in their stroke lengths during the course of the study.

\section{Practical Applications}

Ballistic training program was found to improve the distance and time of start swimming (crawl) in female students in a 
physical education program. A study using this type of exercise program on a large sample of subjects of different ages and both sexes is needed.

\section{References}

1. Atha, J. Strengthening muscle. Exerc Sport Sci Rev. 1981;9:1-73.

2. Brandon R. Strength or power: Which matters most for peak athletic performance? Peak Performance, 2003;187(October), 1(4): 353

3. Eliot B, Wilson G, Kerr G. biomechanical analysis of the sticking region in the bench press. Med Sci Sports Exerc,1989; 21:450-462.

4. Hammett J, Hey W. Neuromuscular adaptation to short-term (4 weeks) ballistic training in trained high school athletes. J Strength Cond Res, 2003;17:556-560.

5. Hirofumi T, David L. Costill., Robert T, William J. Jeffrey J. Dry-land resistance training for competitive swimming. Med Sci Sports Exerc. 1993 ;25(8):952-9.

6. Johns, A.R., Houmard, J.A., Kobe, R.W., HortobJgy, T., Bruno N.J., Wells,.J.M., Shinebarger, M.H. (1992). Effects of taper on swim power, stroke distance, and performance. Human Performance Laboratory and Department of Health, Physical Education, Recreation and Safety. East Carolina University.
Greenville. Med. Sci. Sports Exerc., 1992;24 (10): 1141-1146.

7. Linthorne N. Optimum release angle in the shot put. J Sports Sci, 2001; 19(5): 359-372.

8. Mccoy R, Gregor R, Whiting W, Rich R, Ward P. Kinematic analysis of elite shot putters. Track Technique, 90,1984.

9. Newton R, Murphy A, Humphries B, Wilson G, Kraemer W, Hakkinen, K. Influence of load and stretch shortening cycle on the kinematics, kinetics and muscle activation that occurs during explosive upper-body movements. Eur J Appl Physiol Occup Physiol.; 1997; 75(4):333-42

10. Newton R, Kraemer W. Developing explosive muscular power: implications for a mixed methods training strategy. NSCAJ. 1994;16 :(5):20-3

11. Scheett T. Go Ballistic: 2004 . http://findarticles.com/p/articles/mi_m0801/is_10 65/ai_n6240769/

12. Toussaint HM. Vervoorn K. Effects of specific high resistance training in the water on competitive swimmers. Int. J. Sports Med. 1990;11: 228-233.

13. Zatsiorsky V. Science and Practice of Strength Training. Champaign: Human Kinetics Publishers.45,1995 